\title{
Avaliação da adesividade do ligante asfáltico modificado com lodo têxtil por meio do processamento digital de imagens
}

\author{
Evaluation of the adhesiveness of the asphalt binder modified with textile sludge by means of digital
} image processing

Evaluación de la adhesividad del ligante asfáltico modificado con lodos textiles mediante procesado digital de imagen

\begin{abstract}
Resumo
A adesividade é um importante indicador de qualidade para misturas asfálticas de camadas de rolamento em pavimentos. Consequências frequentes da má adesividade do ligante ao agregado são deslizamento e desagregação, bem como a redução da durabilidade. Assim, é necessária a avaliação e compreensão integral deste fenômeno. Na presente pesquisa, foram utilizadas diferentes abordagens objetivando analisar a adesividade quando há incorporação de lodo têxtil, um resíduo industrial poluente proveniente também das lavanderias têxteis localizadas no APL de Confecções do Agreste Pernambucano, a matrizes asfálticas. O lodo foi adicionado diretamente ao material aderente nos teores de 2,0 e 3,0\% em relação à massa total da mistura, sendo essas amostras comparadas, por meio da adesividade, a de referência, sem lodo. A adesividade foi analisada qualitativamente pelo ensaio convencional de adesividade, descrito pela norma brasileira DNIT ME 078/1994. A área de agregado recoberto por ligante foi calculada por meio do processamento digital de imagens e por fim, a interface da superfície da mistura foi analisada por microscopia petrográfica. Os resultados apontaram que a inserção de lodo na mistura não prejudica a adesividade da mesma, visto que as três amostras não apresentaram decapagem da película e a área recoberta por ligante foi de $100 \%$. A microscopia petrográfica mostrou que a película de mastique (ligante e lodo têxtil) penetrou até mesmo poros de vazios menores, resultado que demonstra que o aumento de viscosidade não prejudicou o espalhamento na superfície do agregado e que as matrizes asfálticas podem ser uma boa forma de aprisionamento do resíduo estudado.
\end{abstract}

Palavras-chave: Adesividade; Lodo têxtil; Misturas asfálticas.

\begin{abstract}
Adhesiveness is an important quality indicator for asphalt mixtures of rolling layers in pavements. Frequent consequences of poor adhesion of the binder to aggregate are slippage and disintegration, as well as reduced durability. Thus, it is necessary to evaluate and fully understand this phenomenon. In the present research, different approaches were used in order to analyze the adhesiveness when there is incorporation of textile sludge, a polluting industrial residue also coming from textile laundries located at the Confeste do APL of Agreste Pernambucano, to asphalt matrices. The
\end{abstract}


sludge was added directly to the adherent material in contents of 2.0 and $3.0 \%$ in relation to the total mass of the mixture, and these samples were compared, by means of adhesiveness, to the reference, without sludge. The adhesiveness was analyzed qualitatively by conventional adhesion test described by Brazilian standard DNIT ME 078/1994. The aggregate area covered by ligand was calculated by means of digital image processing and the mixture surface interface was analyzed by microscopy petrographic. The results showed that the insertion of sludge in the mixture does not affect the adhesion of the mixture, since the three samples did not present pickling of the film and the area covered by binder was $100 \%$. Petrographic microscopy showed that the mastic film (binder and textile sludge) penetrated even smaller void pores, this result demonstrates that the increase in viscosity did not harm the spreading on the aggregate surface and that asphalt matrices can be a good form of imprisonment of the studied waste.

Keywords: Adhesiveness; Textile sludge; Asphalt mixtures.

\section{Resumen}

La adhesividad es un indicador de calidad importante para mezclas asfálticas de capas rodantes en pavimentos. Las consecuencias frecuentes de una mala adhesión del aglutinante al agregado son el deslizamiento y desintegración, así como menor durabilidad. Así, es necesario evaluar y comprender plenamente este fenómeno. En la presente investigación se utilizaron diferentes enfoques para analizar la adhesividad ante incorporación de lodos textiles, residuo industrial contaminante proveniente también de lavanderías textiles ubicadas en Confeste do APL de Agreste Pernambucano, a matrices asfálticas. El lodo se adicionó directamente al material adherente en los contenidos de 2.0 y $3.0 \%$ en relación a masa total de la mezcla, y estas muestras se compararon, mediante adhesividad, con la referencia, sin lodo. La adhesividad se analizó cualitativamente mediante prueba de adhesión convencional descrita por la norma brasileña DNIT ME 078/1994. El área agregada cubierta por ligando se calculó mediante procesamiento de imagen digital y finalmente, la interfase de la superficie de la mezcla se analizó por microscopía petrográfica. Los resultados mostraron que la inserción de lodos en la mezcla no afecta la adherencia, ya que las muestras no presentaron ningún desprendimiento de la película y el área cubierta por aglutinante fue del 100\%. La microscopía petrográfica mostró que la película de masilla (ligante y lodo textil) penetraba poros vacíos aún más pequeños, resultado que demuestra que el aumento de viscosidad no dañó la extensión en la superficie del agregado y que matrices asfálticas pueden ser una buena forma de aprisionamiento de los residuos estudiados.

Palabras clave: Adhesividad; Lodos textiles; Mezclas asfálticas.

\section{Introdução}

O lodo têxtil é o produto final do tratamento de águas residuais das lavanderias de beneficiamento têxtil, presentes de forma significativa no APL de Confecções do Agreste pernambucano, como destacam Silva Filho, Duarte, Sinesio, Silva e Pessôa (2021). Pulverulento quando seco e destorroado a baixa energia, esse resíduo pode conter metais pesados como chumbo, cádmio, manganês, cromo, cobre níquel, além de alumínio, ferro e zinco, provenientes também dos corantes (Cogo, 2011). A variabilidade da composição química desse resíduo torna o processo de tratamento difícil e com alto custo de disposição final.

A fim de diminuir os impactos ambientais causados, diversos autores buscaram alternativas sustentáveis para redirecionamento desse material por meio da incorporação na construção civil. Seja em argamassas cimentícias (Balasubramanian et al., 2006), blocos de concreto (Zhan e Poon, 2015) ou em materiais cerâmicos (Herek et al., 2012; Zanoni, 2013; Aquino et al., 2015). Ademais, o aprisionamento do lodo têxtil em revestimentos asfálticos pode ser interessante, devido às características semelhantes às de fíleres convencionais e ao grande volume em massa requisitado nesse ramo.

Diversos fatores são imprescindíveis para investigar a viabilidade de camadas de revestimento asfáltico como imobilizadoras de resíduos industriais, entre eles, a adesividade. Segundo Abeda (2010), a adesividade garante a resistência adesiva e coesiva do agregado à película de ligante asfáltico. A perda de adesão decorre da entrada de água entre a superfície agregado-ligante, já a perda de coesão se deve ao enfraquecimento das ligações que mantém o conjunto unido e garante sua rigidez (Hirsch, 2007).

Segundo Pereira (2012), o fenômeno da decapagem ocorre quando a superfície de agregado é mais fortemente atraída pela água do que pelo betume. Em geral, o efeito da água somado a capilaridade inerente desenvolve uma ação deletéria às estruturas asfálticas. A umidade favorece o deslizamento da película de asfalto sobre a superfície do agregado e consequente deformação permanente em trilhas de roda (Bernucci, Motta, Ceratti, \& Soares, 2008). Nesse contexto, pode ser observada a redução da resistência à fadiga quando há formação de trincas ou rachaduras, e da durabilidade dos pavimentos. 
A adesividade é uma propriedade que está intimamente ligada à energia de superfície. Segundo Daltin (2012), a tensão superficial ocorre pela resultante desproporcional das forças intermoleculares na superfície e reflete diretamente na viscosidade de um material. Em geral, betumes mais viscosos agregam maior resistência ao deslizamento da película de betume pela umidade que os menos viscosos (Hicks, 1991; Majidzadeh \& Brovold, 1968; Taylor \& Khosla, 1983).

Para os agregados, textura superficial áspera, cobertura limpa e seca e composição química superficial capaz de formar ligações do tipo pontes de hidrogênio, são características desejáveis que favorecem a adesividade (Hicks, 1991). De acordo com Furlan (2006), os agregados que possuem menor concentração de sílica $\left(\mathrm{SiO}_{2}\right)$ em sua composição tendem a desenvolver melhores ligações ao betume que a água, são chamados hidrofóbicos.

No Brasil, a norma DNIT ME 78/1994 define a adesividade como a capacidade do agregado de ser recoberto por ligante asfáltico. No ensaio proposto, a mistura é colocada em estado de condicionamento para impulsionar o deslizamento da película asfáltica sob agregado pela ação d'água. A amostra é classificada qualitativamente como "satisfatória" ou "insatisfatória", de acordo com a avaliação visual de ocorrência ou não do efeito. Devido a importância da adesividade para a qualidade empregada no revestimento asfáltico, outros protocolos podem ser utilizados para análise complementar do fenômeno.

Lucas Júnior e Soares (2018) propõem o método de processamento digital de imagens (PDI) para análise da adesividade agregado-ligante em misturas asfálticas. O procedimento tem o propósito de complementar o estudo da adesividade, por meio de um resultado quantitativo do deslocamento. Através do auxílio de ferramentas computacionais, é feita a discretização espacial, quantização e limiarização dos pixels de imagens das amostras condicionadas. Como resultado, é encontrada a percentagem de área de agregado coberta por ligante não afetada pela ação da água ( $\mathrm{APDI}_{\mathrm{PDI}}$.

Segundo Bernucci et al. (2008), a análise da microscopia petrográfica permite a obtenção de informações importantes sobre a caracterização de partículas. Por tal motivo, sua utilização deve ser estimulada na pavimentação asfáltica. Rocha Filho, Soares, Tavares, Silva, e Ilha (2018), agruparam especificações de conhecimento oral de técnicos e profissionais de laboratório a fim de determinar uma metodologia em etapas sistêmicas da confecção de lâminas petrográficas. Com o uso de microscópio ótico petrográfico e do software AnalySiS, essas lâminas podem ser analisadas de modo a complementar o estudo da interface das misturas asfálticas.

É cada vez mais recorrente o emprego de métodos quantitativos e microestruturais para a análise do fenômeno da adesividade. Portanto serão combinados de modo a proporcionar uma análise mais profunda e integral da interação do ligante asfáltico modificado por lodo têxtil e os agregados, quanto à adesividade. Além disso, será possível a observação da interação microscópica entre esse resíduo e o ligante, e suas possíveis interferências químicas e físicas.

\section{Metodologia}

Neste trabalho serão analisados os efeitos da adesividade quando da incorporação de lodo têxtil ao concreto betuminoso usinado a quente (CBUQ). Segundo os parâmetros definidos pela dosagem Marshall e em consonância a norma DNIT ES 31/2006 para CBUQ, Faixa "C", foi adotada a inclusão de lodo têxtil como material fíler nos teores 2 e 3,0\% em relação à massa total da mistura. Essas adições representam respectivamente 36,4 e 54,5\% em relação ao teor de ligante CAP 50/70 de 5,5\% adotado. Como descrevem Pereira et al. (2018), esta pesquisa tem natureza quali-quanti, onde são analisados aspectos inerentes a adesividade tanto de forma qualitativa, pelo método convencional, bem como quantitativa pelo método de processamento digital de imagem conforme Lucas Júnior \& Soares (2018), correlacionando com as características químicas e microestruturais.

\subsection{Fluorescência de Raios-X (FRX)}

Inicialmente, para a determinação dos elementos químicos presentes no lodo têxtil e suas respectivas proporções foi utilizada a Fluorescência de Raios-X. Esse ensaio é baseado na excitação do material com raios-X e decorrente energia de 
radiação de fluorescência emitida para estudo de sua composição. A análise foi feita por meio do auxílio do espectrofotômetro de fluorescência de raios-X, da marca Rigaku, modelo Primini.

\subsection{Viscosidade rotacional}

Após a adição do lodo têxtil ao ligante foi realizado o ensaio de viscosidade a altas temperaturas segundo a ABNT NBR 15184/2004 para a amostra de referência sem lodo, e com adições de 2 e $3 \%$ de lodo em relação à mistura total. O ensaio consiste em através de um viscosímetro rotacional do tipo Brookfield traduzir o torque necessário para girar uma haste a velocidade constante no recipiente da amostra termostaticamente controlado. Para cada uma das amostras utilizou-se o spindle 21. Como o lodo é um material pulverulento, é esperado um incremento deste parâmetro.

\subsection{Agregado Graúdo - Adesividade a Ligante Betuminoso - DNIT ME 78/1994}

Para esse ensaio, a amostra é preparada com 500g de agregado graúdo, passante pela peneira 19,0 mm e retido pela 12,5 $\mathrm{mm}$, e 17,5g de ligante asfáltico modificado com lodo têxtil. O agregado deve ser lavado, colocado dentro d'água destilada durante 1 min e, em seguida, levado para estufa a temperatura de $120^{\circ} \mathrm{C}$ durante 2 horas. Já a massa de cimento asfáltico deve ser aquecida em estufa a $100^{\circ} \mathrm{C}$. É colocada uma camada de ligante sob o agregado até que toda a sua superfície seja envolvida. Em um frasco de vidro, a mistura é coberta de água destilada e segue para estufa onde é submetida a uma temperatura de $40{ }^{\circ} \mathrm{C}$ durante 72 horas. Na Figura 1, pode-se observar a amostra da mistura, submersa em água. O resultado é tido como satisfatório se o agregado estiver completamente coberto por filme asfáltico ao fim de 72 horas. Se for notado qualquer deslizamento da película, o resultado será considerado insatisfatório.

Figura 1. Ensaio qualitativo de adesividade.

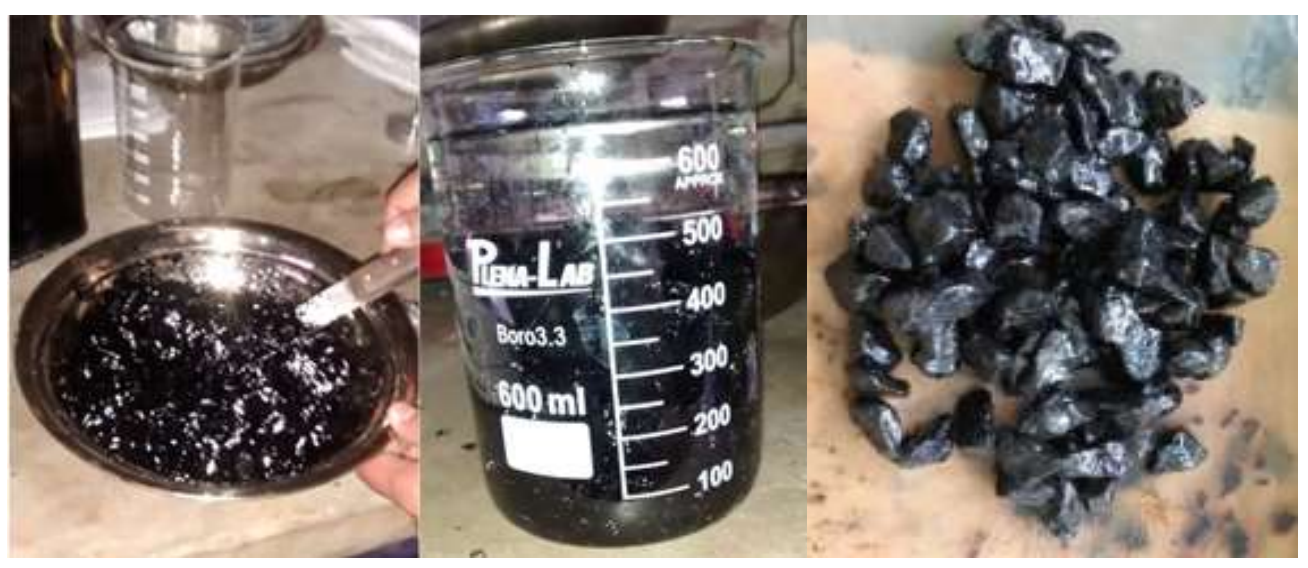

Fonte: Autores (2021).

\subsection{Processamento Digital de Imagens}

O método de avaliação da adesividade com o uso de processamento digital de imagem proposto por Lucas Júnior \& Soares (2018) baseia-se através de implementação no software Matlab, determinando o percentual de área do agregado recoberto por ligante asfáltico. $\mathrm{O}$ ensaio foi feito a partir das amostras obtidas ao final do teste de adesividade explicitado no item anterior. As misturas asfálticas de referência ( $0 \%$ e com 2,0\% e 3,0\% de lodo têxtil são dispostas espaçadamente sobre um fundo branco e são capturadas três imagens por câmera de smartphone, como mostrado na Figura 2. 
Figura 2. Imagem para Processamento Digital.

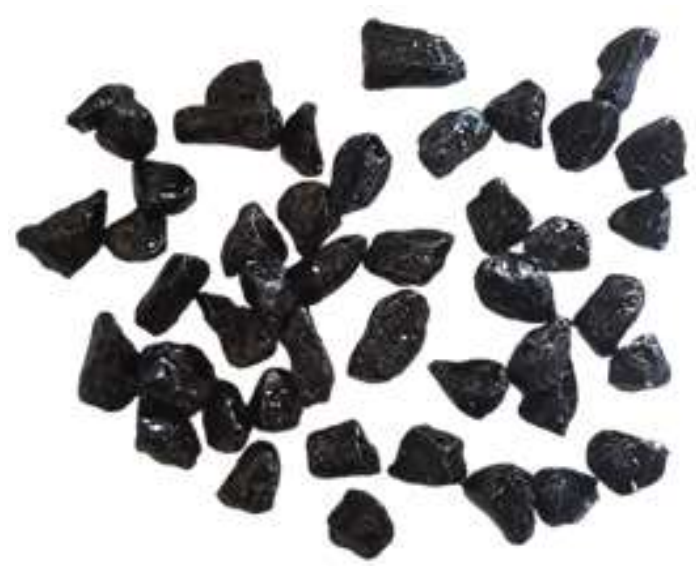

Fonte: Autores (2021).

Um histograma de frequência de pixels é determinado para traduzir a distribuição de tons de cinza da imagem. Duas regiões de interesse são explicitadas através da segmentação por limiarização: a do agregado e a do agregado recoberto por ligante. O comando "BWAREA" é utilizado para calcular cada uma das áreas de interesse. Sendo $\mathrm{P}_{\mathrm{L}}$ o número de pixels do ligante e $\mathrm{P}_{\mathrm{A}}$ o número de pixels do agregado, o percentual da área coberta pelo ligante asfáltico $\mathrm{A}_{\mathrm{PDI}}$ é calculado pela seguinte equação:

$$
A_{P D I}=\frac{P L}{P A} \times 100 \text { (Equação 1) }
$$

\subsection{Microscopia Petrográfica Óptica}

Para a avaliação das interações físicas microscópicas, foi realizada microscopia petrográfica óptica do ligante adicionado lodo têxtil e sua interação com o agregado. A técnica de preparação das lâminas seguiu a metodologia empregada por Rocha Filho et al. (2018). Foi realizado o corte da amostra de agregado recoberto por ligante modificado a fim de obter forma retangular e o polimento de toda a superfície com o uso de abrasivos. Após a lavagem com sabão de pH neutro e água corrente, a esquírola e a lâmina de vidro foram colocadas em estufa a temperatura entre 50 e $60^{\circ} \mathrm{C}$ para secagem total. A união das peças foi feita com auxílio de resina e colocada em estufa a $55^{\circ} \mathrm{C}$ para secagem. Por fim, foi feito mais um polimento a fim de obter lâminas com espessura padrão de $0,03 \mathrm{~mm}$. A análise das lâminas foi realizada utilizando Microscópio ótico petrográfico Olympus bx40, Câmera sc30 e software AnalySiS, como mostra a Figura 3. 
Figura 3. Confecção de lâminas petrográficas e microscopia.

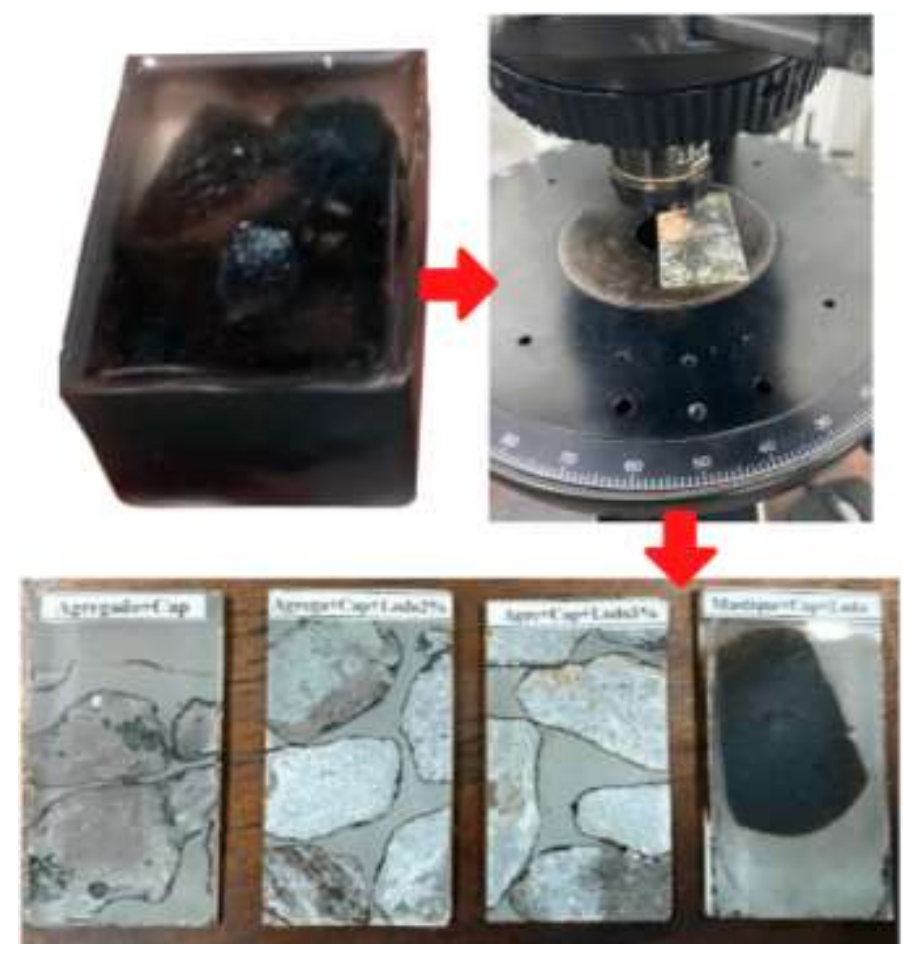

Fonte: Autores (2021).

\section{Resultados e Discussão}

\subsection{Fluorescência de Raios-X (FRX)}

Como produto do ensaio de FRX e correção do percentual de matéria orgânica, obtido por meio da análise termogravimétrica, foi elaborada a Tabela 1. Sendo a porção de matéria orgânica cerca de $20 \%$, o total dos valores obtidos pelo equipamento que não a mensura, representam cerca de $80 \%$. É possível observar que o lodo têxtil é formado majoritariamente por óxido de cálcio $(\mathrm{CaO})$, óxido de magnésio $(\mathrm{MgO})$ e dióxido de silício $\left(\mathrm{SiO}_{2}\right)$. Esse resultado demonstra grande similaridade à composição de fíleres convencionais, como a cal e o pó calcário. Lucas Júnior, Babadopulos e Soares (2019) investigaram a composição química dos agregados minerais na adesividade. Os resultados mostraram que aqueles com maiores teores de $\mathrm{CaO}$ e $\mathrm{Fe}_{2} \mathrm{O}_{3}$ denotaram maior área coberta por ligante asfáltico, ou seja, sendo benéficos a adesividade, enquanto os com maiores teores de $\mathrm{SiO}_{2}$ tiverem a adesividade prejudicada. Outros óxidos, como o de magnésio e alumínio não demonstraram influência positiva ou negativa.

Tabela 1. Composição química do lodo têxtil.

\begin{tabular}{cc|cc|cc}
\hline \multicolumn{7}{c}{ Componente / Percentual (\%) } \\
$\mathrm{CaO}$ & 28,18 & $\mathrm{SO}_{3}$ & 4,34 & $\mathrm{MnO}$ & 1,63 \\
$\mathrm{MgO}$ & 20,98 & $\mathrm{Al}_{2} \mathrm{O}_{3}$ & 3,62 & $\mathrm{Fe}_{2} \mathrm{O}_{3}$ & 1,44 \\
$\mathrm{SiO}_{2}$ & 14,81 & $\mathrm{Cl}$ & 2,18 & Orgânicos* & 20,00 \\
\hline
\end{tabular}

*Valores obtidos pelo (TGA/DTG) ** Outros 2,82\%. Fonte: Autores (2021).

\subsection{Ensaio de Viscosidade Rotativa (ABNT NBR 15184)}

Observando as curvas de viscosidade na Figura 4 percebe-se que a baixas temperaturas os ligantes modificados com o lodo têxtil apresentam maior distinção do ligante padrão sendo decrementada com o aumento de temperatura. As variações 
podem chegar a 37,5 e 59,2\% para 2 e 3\% de adição de lodo têxtil, respectivamente. Segundo Hu, Fan, Li e Fuentes (2019), o aumento da porcentagem de resíduo é diretamente proporcional à viscosidade mensurada.

Figura 4. Propriedades do CAP 50/70 modificado com lodo têxtil.

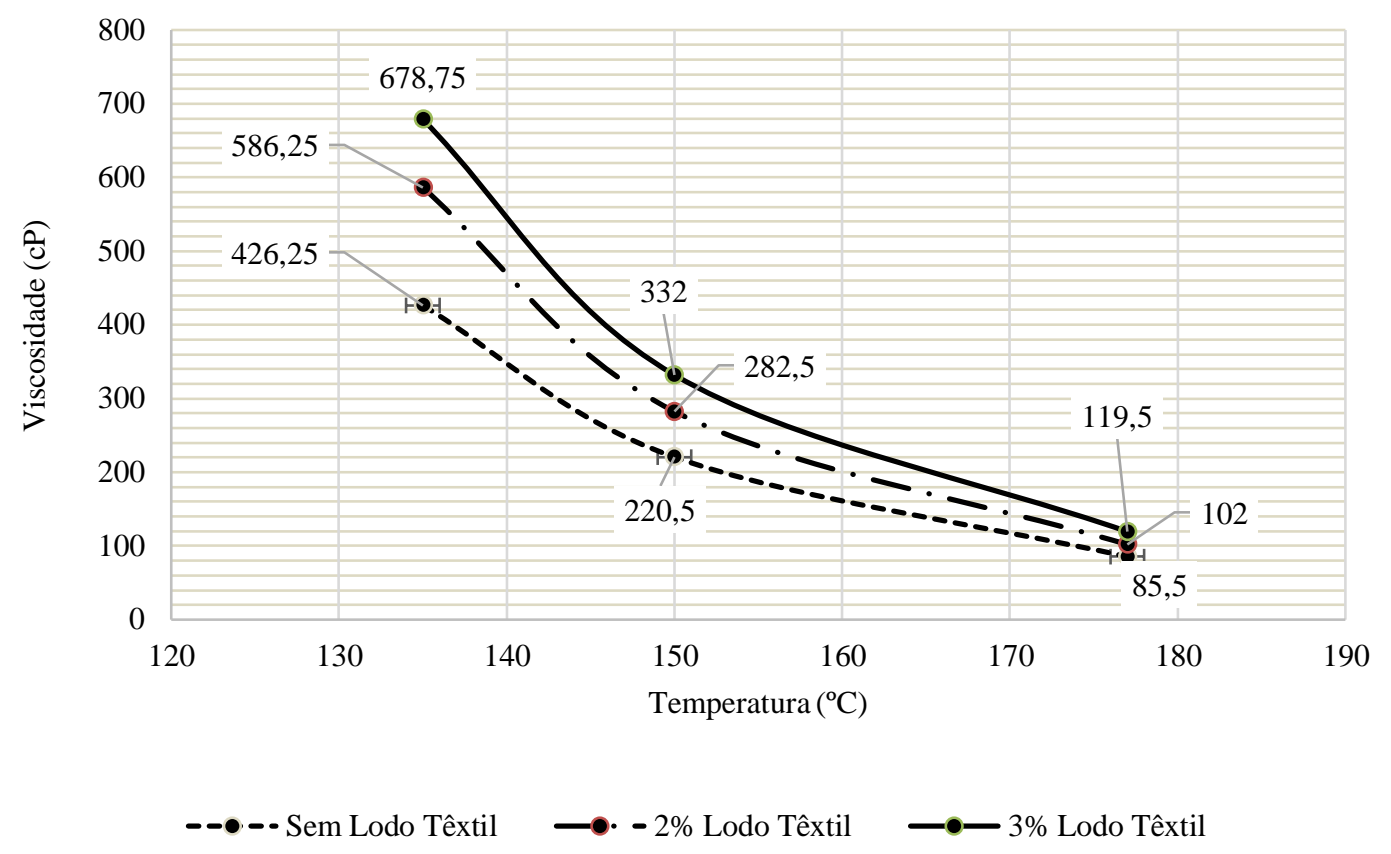

Fonte: Autores (2021).

\subsection{Ensaio de adesividade (DNIT ME 078/1994) e PDI}

A adesividade do agregado na amostra de referência (0\%), bem como nas amostras de 2,0\% e 3,0\% de lodo têxtil não apresentaram deslocamento da película de ligante. Assim, obtiveram resultado satisfatório pelo ensaio de adesividade convencional previsto pela norma DNIT ME 078/1994. Por meio do processamento digital de imagens, cada imagem foi analisada minuciosamente, a fim de encontrar os valores a serem utilizados na limiarização, conforme exposto na Figura 5. Os resultados desse processo apontaram que a adição do lodo têxtil não ocasionou perdas de adesão e coesão entre as faces do agregado e a película de agregado denotando $\mathrm{A}_{\mathrm{PDI}}=100 \%$ em cada uma das amostras. Os valores usados como limiares encontram-se na tabela 2. Esse resultado encontra-se em consonância com os demais autores que também analisaram misturas classificadas como "satisfatórias" pelo ensaio de adesividade descrito nas normas ME DNIT 078/1994 (Lucas Júnior; Babadopulos e Soares, 2018). 
Figura 5. Limiarização das amostras.
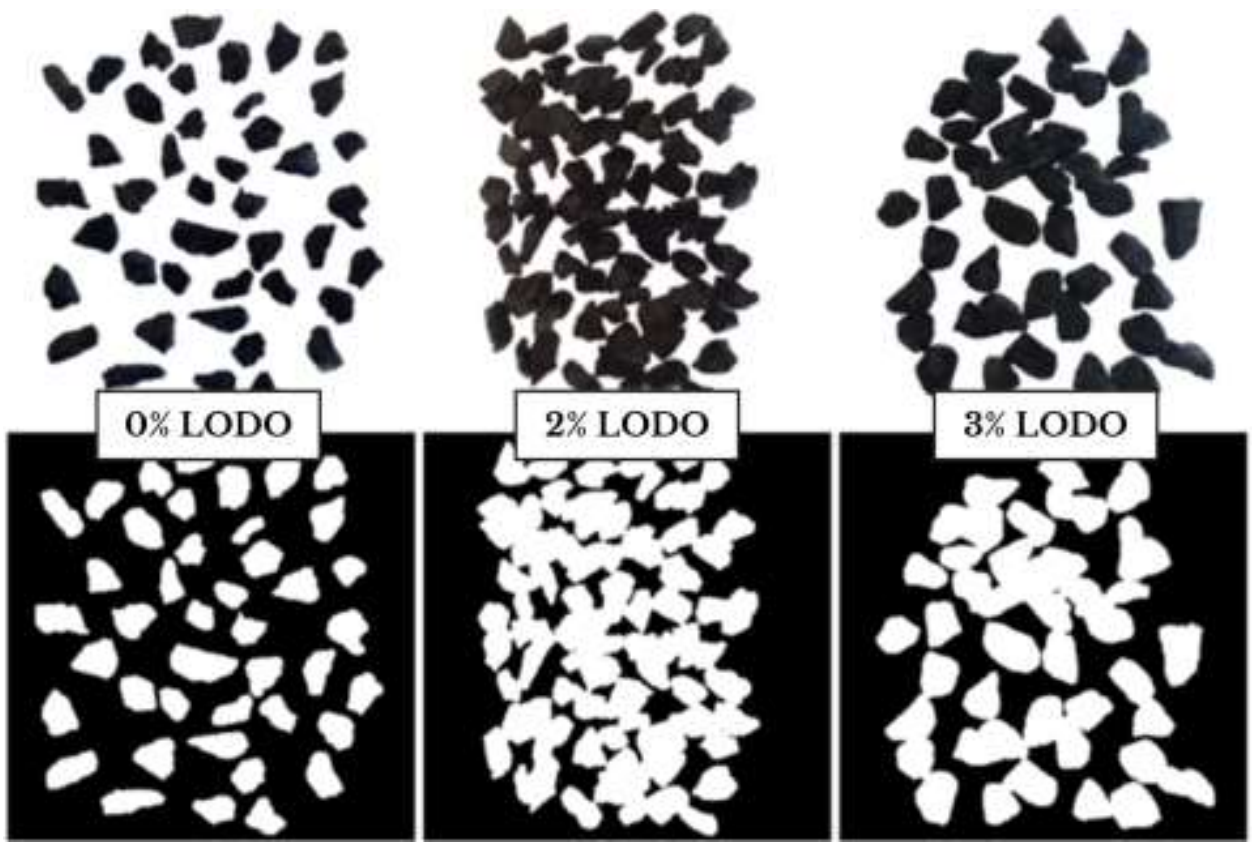

Fonte: Autores (2021).

Tabela 2. Processamento Digital de Imagens.

\begin{tabular}{|cccc|}
\hline Teor de Lodo & $\mathbf{0 \%}$ & $\mathbf{2 , 0 \%}$ & $\mathbf{3 , 0 \%}$ \\
\hline Limiares (T) & $0.695 \mid 0.695$ & $0.540 \mid 0.540$ & $0.668 \mid 0.668$ \\
\hline APDI & $100 \%$ & $100 \%$ & $100 \%$ \\
\hline
\end{tabular}

Fonte: Autores (2021).

\subsection{Microscopia Petrográfica Óptica}

A partir da microscopia das lâminas petrográficas confeccionadas, foi possível observar de forma detalhada o modo como o lodo têxtil e ligante asfáltico se comportam entre si para formar o mastique e dessa junção com a superfície do agregado aderido. Na Figura 6, estão mostradas as interfaces entre ligante asfáltico e agregado. Em (I), a forma de referência sem adição de lodo, bem como em (II) $2 \%$ e (III) $3 \%$ de lodo, pode-se notar que o espalhamento do ligante se deu por toda a superfície do agregado, ocupando, até mesmo, vazios de poros menores. Esse resultado indica que o incremento da viscosidade pela adição de partículas finas de lodo, explicitado em 3.2, não se mostrou prejudicial à adesividade. Ao mesmo tempo, películas mais espessas podem contribuir para prevenir a oxidação acelerada pela incidência de luz e ar, protegendo a estrutura do dano por umidade (Chadbourn, 2000). 
Figura 6. Interfaces da película de ligante ao agregado.
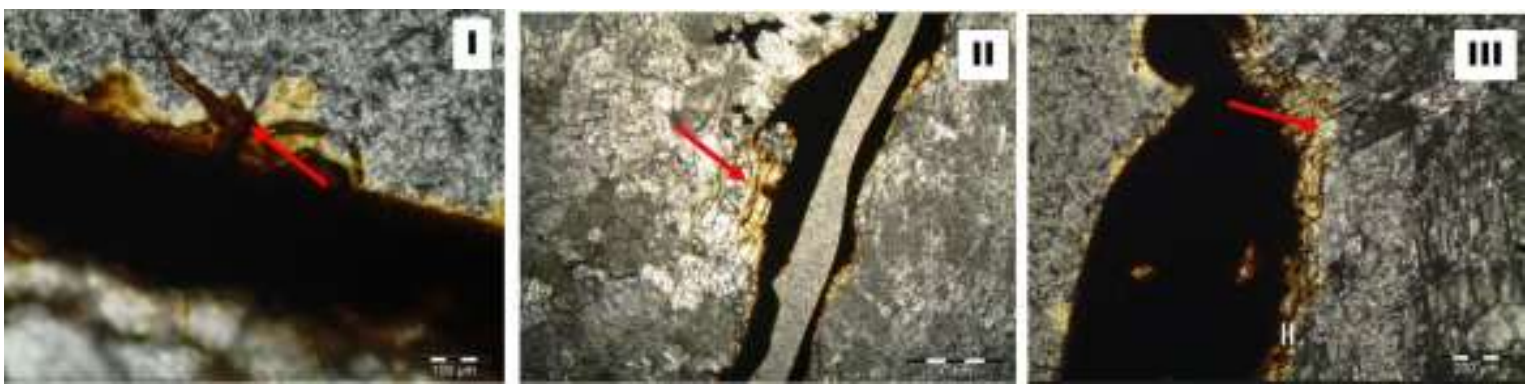

Fonte: Autores (2021).

Quanto à capacidade de aprisionamento das partículas de lodo têxtil ao cimento asfáltico de petróleo, as imagens aproximadas contribuem para uma resposta positiva. Os resultados mostram a presença de minerais opacos (de brilho metálico) e minerais claros denotando a incorporação de compostos diferentes. Na Figura 7, pode-se observar que não há a formação de espaços vazios ou aglutinação de lodo. Esse efeito indica que a dispersão dos grãos de lodo se dá por todo o corpo do ligante.

Figura 7. Microscopia Mastique.

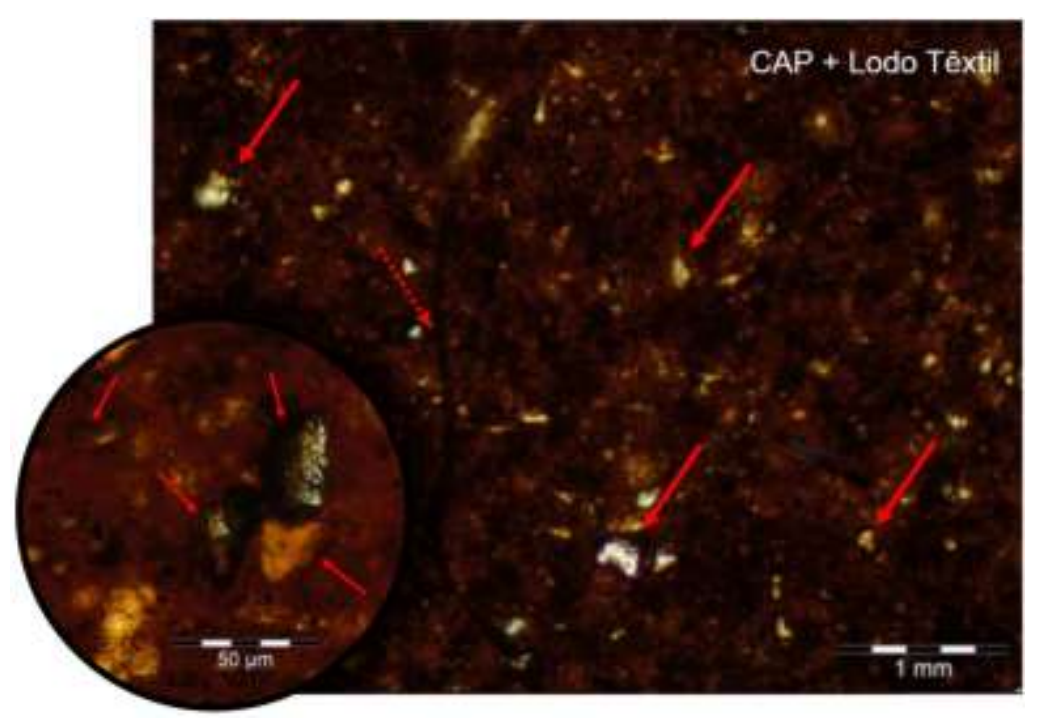

Fonte: Autores (2021).

Além disso, é possível visualizar no ponto indicado com a seta pontilhada a presença de um fio, este possivelmente de origem têxtil de algodão, pode vir a conferir um certo auxílio nas propriedades coesivas e na resistência à tração.

\section{Conclusão}

Os resultados do processamento digital de imagens (PDI) ratificaram de forma quantitativa os resultados obtidos de forma qualitativa pela metodologia do DNIT ME 078/1994. Em ambas as metodologias o ligante modificado com lodo têxtil não apresentou prejuízo a adesividade entre o ligante e os agregados. Além disso, sugere uma possível melhoria nesse parâmetro devido a presença prioritária de óxido de cálcio $\mathrm{CaO}$, além da presença de óxidos férricos $\mathrm{Fe}_{2} \mathrm{O}_{3}$. Sobretudo também pelo acréscimo da viscosidade, foi possível observar que mesmo o ligante mais viscoso, foi capaz de ancorar nas rugosidades e poros do agregado. Por fim, os resultados mostraram que o resíduo foi completamente envolvido pelo ligante, indicando um completo aprisionamento do mesmo, assim denotando a possibilidade de aplicação como constituinte de camadas de revestimento asfáltico. 
Recomenda-se para trabalhos futuros, uma comparação com ensaios de dano por umidade induzida (DUI), bem como observar quantitativamente a fixação deste resíduo na matriz asfáltica por meio de uma análise ambiental.

\section{Referências}

Abeda. (2010). Aditivos orgânicos melhoradores de adesividade - Usos e benefícios. Informativo Técnico No 1-Junho 2010 - Comissão Técnica da Abeda. Associação Brasileira das Empresas Distribuidoras de Asfaltos.

Associação Brasileira de Normas Técnicas. (2004). NBR 15184: Materiais asfálticos - Determinação da Viscosidade Brookfield.

Aquino, R. C. (2015). Adição de resíduo de lodo da indústria têxtil na produção de blocos cerâmicos de vedação. Revista Eletrônica de Materiais e Processos, $10,29-35$.

Balasubramanian, J., Sabumon, P. C., Lazar, J. U., \& Ilangovan, R. (2006). Reuse of textile effluent treatment plant sludge in building materials. Waste Management, 26(1), 22-28.

Bernucci, L. B., Motta, L. M. G. da, Ceratti, J. A. P., \& Soares, J. B. (2008). Pavimentação asfáltica: formação básica para engenheiros. Petrobras, Abeda.

Chadbourn, B. A., Crow, B.L., Newcomb, D., Skok, Jr., E. L., \& Spindles, S. (2000). The effect of voids in mineral aggregate (VMA) on hot-mix asphalt pavements. Final Report No. 2000-13. Department of Transportation - Minnesota.

Cogo, M. da C. (2011). Estudo de Caracterização e Disposição dos Resíduos de uma Indústria Têxtil do Estado do Rio Grande do Sul. Universidade Federal do Rio Grande do Sul.

Daltin, D. (2011). Tensoativos: química, propriedades e aplicações. Blucher.

Departamento Nacional de Infraestrutura e Transportes. (1994). DNIT ME 78: Método de Ensaio. Misturas Betuminosas - Adesividade de Agregado Graúdo a Ligante Betuminosa.

Furlan, A. P. (2006). Considerações acerca da adesão e da susceptibilidade à umidade de misturas asfálticas densas à luz de algumas propriedades mecânicas . Universidade de São Paulo.

Herek, L. C. S., Hori, C. E., Reis, M. H. M., Mora, N. D., Tavares, C. L. G. \& Bergamasco, R. (2012). Characterization of ceramic bricks incorporated with textile laundry sludge. Ceramics International, 38, 951-959.

Hicks, R. G. (1991). Moisture damage in asphalt concrete. National Cooperative Highway Research, Program Synthesis of Highway Practice Transportation Research Board.

Hirsch, F. (2007). Estudo do comportamento de misturas asfálticas preparadas com diferentes tipos. Universidade Regional do Noroeste do Estado do Rio Grande do Sul.

Hu, X., Fan, S., Li, X., \& Fuentes, L. (2019). Exploring the feasibility of using reclaimed paper-based asphalt felt waste as a modifier in asphalt-binders. Construction and Building Materials.

Lucas Júnior, J. L. O., Jr., Babadopulos, L. F. A. L., \& Soares, J. B. (2019). Aggregate-binder adhesiveness assessment and investigation of the influence of morphological and physico-chemical properties of mineral aggregates. Road Materials and Pavement Design. 10.1080/14680629.2019.1588773

Lucas Júnior, J. L. O., \& Soares, J. B. (2018). Desenvolvimento de metodologia para avaliação da adesividade agregado-ligante com o uso de processamento digital de imagem. Transportes. 10.14295/transportes.v27i1.1552

Majidzadeh, K., \& Brovold, F. N. (1968). State of Art: Effect of water on bitumen-aggregate mixtures. Highway Research Board, Special Report No. 98, 77p.

Pereira, A. S., Shitsuka, D. M., Parreira, F. J. \& Shitsuka, R. (2018). Metodologia da pesquisa científica. 67-69.

Pereira, G. da S. (2012). Aditivos Orgânicos Melhoradores de Adesividade. Boletim Técnico SINICESP.

Rocha Filho, D., Soares, D. T., Tavares, A. P.; Silva, G. S. N., \& Ilha, L. M. (2018). Confecção de lâminas delgadas para análise de rocha. Universidade Federal do Pampa.

Silva Filho, A. R. A., Duarte, A. D., Sinesio, E. P., Silva, G. L., \& Pessôa, S. G. S. (2021). Classification, characterization and diagnosis of Jeans Processing Laundries in the City of Caruaru-PE, in Agreste Pernambucano. Research, Society and Development, 10(1), e57810112186.

Taylor, M. A., \& Khosla, N. P. (1983). State of the art: Stripping on asphalt pavement. Transportation Research Record 911.

Zanoni, S. M. (2013). Reutilização de resíduos de indústria têxtil como matéria-prima em cerâmica vermelha. Universidade do Extremo Sul Catarinense.

Zhan, B. J. \& Poon, C. S. (2015). Study on feasibility of reutilizing textile effluent sludge for producing concrete blocks. Journal of Cleaner Production, (101), 174-179. 